\title{
1 Calibration of Strain Gauged Square Tunnels for Centrifuge
}

\section{Testing}

${ }^{a}$ Aristotle University, Department of Civil Engineering, Thessaloniki, Greece

${ }^{\mathrm{b}}$ University of Nottingham, Faculty of Engineering, Nottingham, UK

${ }^{\mathrm{c}}$ University of Cambridge, Schofield Centre, Cambridge, UK

Corresponding author: Grigorios Tsinidis, Dr. Civil Engineer, MSc, Department of Civil Engineering, Research Unit of Geotechnical Earthquake Engineering and Soil Dynamics, Aristotle University of Thessaloniki, PO BOX 424 GR-54124, Thessaloniki, Greece, tel: +302310994208, e-mail: gtsinidi@ civil.auth.gr

Abstract: A series of dynamic centrifuge tests was conducted on square aluminum tunnelmodels embedded in dry sand. The tests were carried out at the Schofield Centre of the Cambridge University Engineering Department, aiming to investigate the dynamic response of these type of structures. An extensive instrumentation scheme was employed to record the soil-tunnel system response, which comprised of miniature accelerometers, total earth pressures cells and position sensors. To record the lining forces, the model tunnels were strain gauged. The calibration of the strain gauges, the data from which was crucial to furthering our understanding on the seismic performance of box-type tunnels, was performed combining physical testing and numerical modelling. This technical note summarizes this calibration procedure and highlighting the importance of advanced numerical simulation in the calibration procedure of complex construction models.

Keywords: Centrifuge modelling; Calibration; Strain Gauges; Numerical analysis

\section{Introduction}

30 Large underground structures (e.g. subways, metro stations, underground parking lots, utility tunnels) have a vital socio-economic role - being a crucial part of the transportation and utility networks in an urban area. To prevent disruption arising from earthquake induced damage, rigorous seismic design procedures need to be developed, verified and implemented. In this 
context a range of different experimental researches have been carried out over recent years aiming at the investigation of the seismic response of underground strcutures and tunnels (Shabayama et al., 2010, Lanzano et al., 2012; Cilingir and Madabhushi, 2011a, 2011b, 2011c; Chian and Madabhushi, 2011; Chen et al., 2013; Chen and Shen, 2014; Tsinidis et al., 2015a; Ulgen et al., 2015; Abuhajar et al., 2015). Experimental studies have been also conducted for the evaluation of the seismic behavior of actual case studies during retrofitting projects (Adalier et al., 2003; Chou et al., 2010). Although there are some published experimental programs investigating the behaviour of rectangular embedded structures, where strain gauges were employed to record the lining forces (e.g. Chen and Shen, 2014), no clear reference is given for the calibration of these crucial instruments.

This lack of reference, along with the need for more artificial 'case studies', motivated the realisation of the collaborative experimental project TUNNELSEIS, through the EU funded research project SERIES. Within the framework of this research project, the seismic response of shallow square tunnels embedded in dry sand was investigated by means of dynamic centrifuge tests. The tests were carried out at the geotechnical centrifuge facility of the Schofield Centre, University of Cambridge. This technical note summarizes the calibration procedure followed for the resistance strain gauges, which were used to record the lining forces and highlighting the significance of advanced numerical simulation in the calibration procedure of complex construction models.

\section{Description of centrifuge tests undertaken}

Three dynamic centrifuge tests were performed on square tunnel models embedded in dry Hostun HN31 sand, reconstituted at two different relative densities of about $50 \%$ and $90 \%$.

Two square tunnel models were manufactured and tested, namely: a relative rigid one having a thickness of $2 \mathrm{~mm}$ and a more flexible one having a thickness of $0.5 \mathrm{~mm}$ (Fig. 1). The rigid model was made of an extruded section of 6063A aluminum alloy, while the flexible model was manufactured by folding a 33swg soft aluminum foil to form the square section and joined by means of a weld at the centre of the invert slab of the tunnel. Both the models were $100 \mathrm{~mm}$ wide, while the length was $220 \mathrm{~mm}$ for the rigid model and $210 \mathrm{~mm}$ for the flexible one. The thickness of the linings was selected so as to study the effects of tunnel flexibility at extreme ends. To simulate more realistically the soil-structure interface, Hostun sand was stuck to the external face of the tunnel-models, creating a rough surface. 
a.

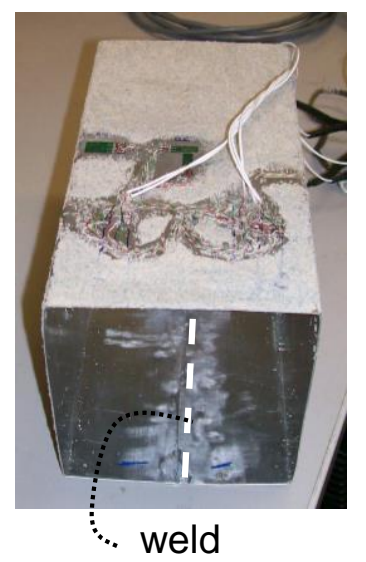

b.

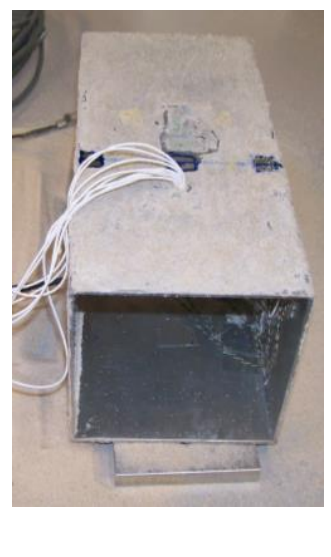

Fig. 1. (a) Flexible tunnel, (b) Rigid tunnel

A typical model layout is presented in Fig. 2. A dense instrumentation scheme was implemented to record the soil-tunnel systems response, comprising of miniature accelerometers, linear variable differential transformers (LVDTs), draw wire potentionmeters (POTs), miniature total earth pressure cells (PCs) and resistance strain gauges to measure the internal forces of the lining at several locations (axial and bending moment strains). Details about the model preparation, setups, and representative experimental data may be found in Tsinidis et al. (2014; 2015b; 2015c).
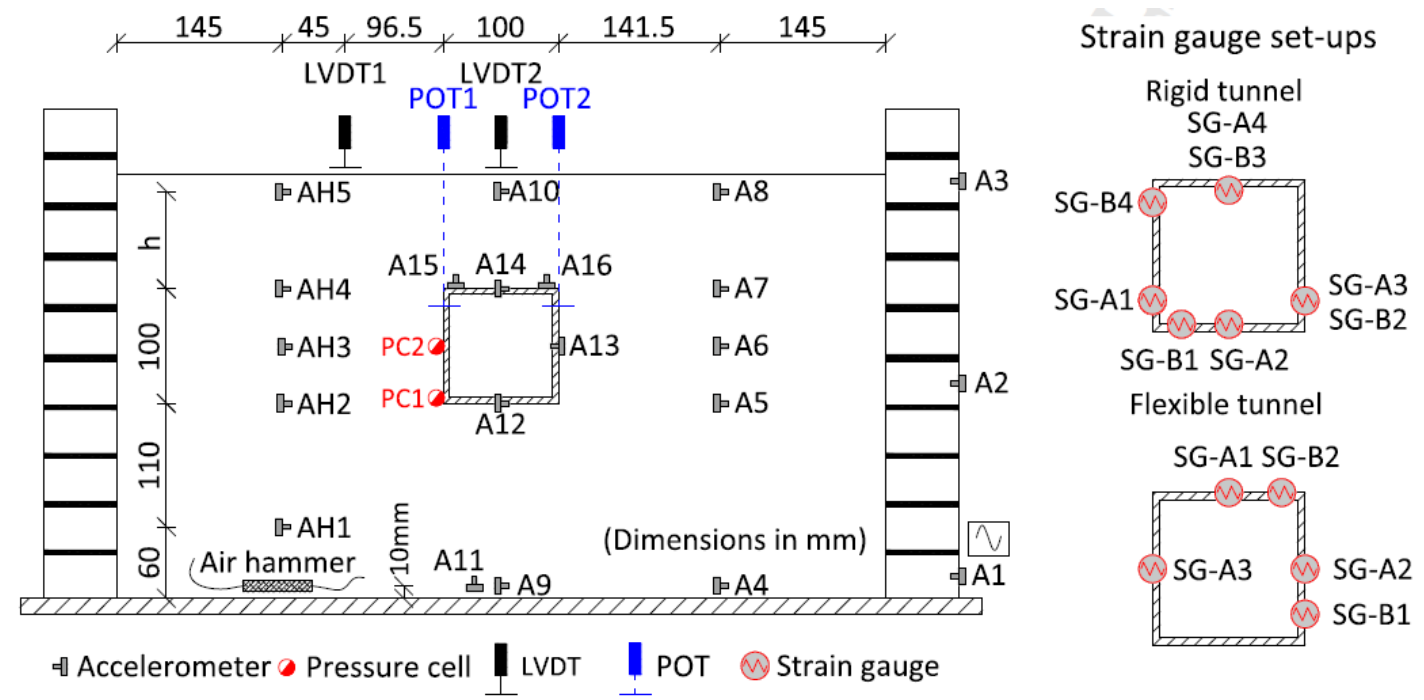

Fig. 2. Typical models layout $(\mathrm{h}=60 \mathrm{~mm}$ for flexible tunnel, $100 \mathrm{~mm}$ for rigid tunnel)

\section{Strain gauging regime}

Resistance strain gauges (TML FLA-6-350-23) were attached to the inner and outer face of the tunnels to measure the bending moment and the axial force (bending and axial strains) at several locations around the tunnel lining (Fig. 2). Eight sets of gauges were used for the rigid 
83

tunnel, with four of them recording the bending moments near the tunnel corners and at the middle of the roof slab (SG-B1, SG-B2, SG-B3 and SG-B4 in Fig. 2) and four of them recording the axial forces in the walls and the slabs of the model tunnel (SG-A1, SG-A2, SGA3, SG-A4 in Fig. 2). Similarly, five sets of strains gauges were used for the flexible tunnel, namely; two sets were recording the bending moments near the tunnel corners (SG-B1, SGB2 in Fig. 2) and three sets were recording the axial forces in the walls and the roof slab (SGA1, SG-A2, SG-A3 in Fig. 2).

To achieve the greatest possible accuracy full Wheatstone bridges were used with two gauges on the inside of the tunnel and two on the outside (Fig. 3). A full bridge allows for strains which arise from alternative sources to be removed, for example the effect of temperature changes, axial forces (in the case of the bending gauges) and bending moments (in the case of the axial gauges).

a.

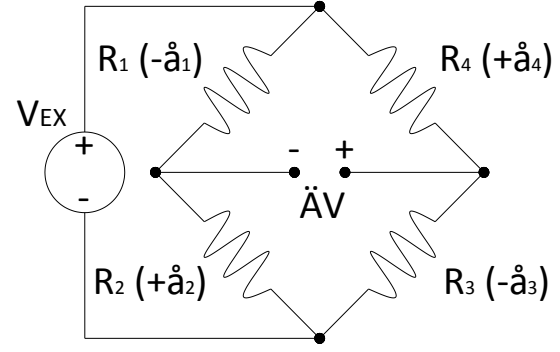

b.

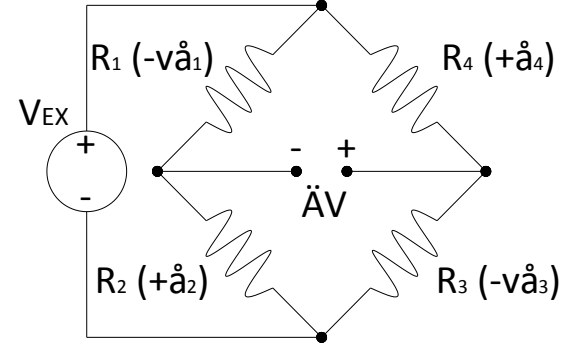

Fig. 3. Typical circuit layouts for (a) bending moment strain gauges, (b) axial force strain gauges

The normal procedures with regard to adhering the gauges to the tunnel were followed. In particular, to record the lining bending moments, the gauges were arranged by attaching a pair of arms on the external face of the lining (e.g. $R_{1}$ and $R_{3}$ in Fig. $3 a$ ) and a second pair on the internal face (e.g. $\mathrm{R}_{2}$ and $\mathrm{R}_{4}$ in Fig. 3a). An application of an excitation Voltage $V_{e x}$ at the extremities of the circuit causes a Voltage variation $\Delta V$ that can be measured with a galvanometer, as illustrated in Fig. 3. According to the wiring pattern, the Voltage ratio is proportional to the average deformation $\varepsilon$ of the gauges:

$$
\frac{\Delta V}{V_{e x}}=\frac{K_{g f}}{4} \varepsilon=\frac{K_{g f}}{4}\left(-\varepsilon_{1}+\varepsilon_{2}-\varepsilon_{3}+\varepsilon_{4}\right)
$$

where: $K_{g f}$ is the gauge factor and $\varepsilon_{i}$ is the deformation of the $\mathrm{i}^{\text {th }}$ arm of the bridge. Assuming a linear elastic response for the lining, the deformations of the arms may be computed, as follows:

$$
\varepsilon_{1}=\varepsilon_{3}=\frac{N}{E A}+\frac{M}{E I} \times \frac{t}{2}, \quad \varepsilon_{2}=\varepsilon_{4}=\frac{N}{E A}-\frac{M}{E I} \times \frac{t}{2}
$$


where: $t$ is the thickness of the lining, $E I$ is the flexural stiffness of the lining, $E A$ is the axial stiffness of the lining, $M$ is the bending moment at the specific location of the lining and $N$ is the axial load at the specific location of the lining. By substituting the arm deformations in Eq. 1, the following expression is obtained for the Voltage change:

$$
\left\{\frac{\Delta V}{V_{e x}}\right\}_{M}=-K_{g f} \times \frac{M}{E I} \times \frac{t}{2}=K_{m} \times M
$$

Eq. 3 implies that the measured Voltage $\Delta V$ is directly proportional to the bending moment at the specific section, through the calibration factor $K_{m}$ and the input Voltage $V$. In this regard, it is related to known geometrical and mechanical parameters of the model.

Another bridge arrangement was implemented for the axial force strain gauges (Fig. 3b). A pair of gauges $\left(\mathrm{R}_{2}\right.$ and $\left.\mathrm{R}_{4}\right)$ was attached in the circumferential direction, while a second pair of gauges $\left(\mathrm{R}_{1}\right.$ and $\mathrm{R}_{3}$ ) was aligned perpendicularly, in order to form a couple of Poisson's gauges. Following the elastic theory, the arm deformations are now given by the following expressions:

$$
\begin{array}{ll}
\varepsilon_{1}=-v\left(\frac{N}{E A}+\frac{M}{E I} \times \frac{t}{2}\right), & \varepsilon_{2}=\frac{N}{E A}+\frac{M}{E I} \times \frac{t}{2}, \\
\varepsilon_{3}=-v\left(\frac{N}{E A}-\frac{M}{E I} \times \frac{t}{2}\right), & \varepsilon_{4}=\frac{N}{E A}-\frac{M}{E I} \times \frac{t}{2}
\end{array}
$$

where: $v$ the Poison ratio of the aluminium model. By substituting again the arm deformations in Eq. 1, the following expression is obtained for the Voltage change:

$$
\left\{\frac{\Delta V}{V_{e x}}\right\}_{N}=(1+v) \times \frac{K_{g f}}{2} \times \frac{N}{E A}=K_{n} \times N
$$

Similar to the bending moment gauges, the measured $\Delta V$ is directly proportional to the axial force at the specific section through the calibration factor $K_{n}$ and the input Voltage $V$.

\section{Calibration procedure}

The calibration factors for both the axial and the bending moment strain gauges were derived for simple static loading patterns. For each loading case, the model was incrementally loaded and unloaded by adding and removing weights, while the output Voltage from each strain gauge bridge was recorded for each loading step. The loading systems (e.g. loading locations, fixities) were selected to ensure the elastic response of the model tunnels and therefore they were slightly different between the flexible and the rigid tunnel, as described in the following sections. Through these procedures, Voltage-mass calibration curves were derived. To come 
out with the final internal force-Voltage calibration curves and thus with the final calibration

139 factors, the static configurations were properly simulated and analyzed, by means of 3D static

140 analyses, using the general purpose finite element code ABAQUS (ABAQUS, 2012). This

141 numerical approach was selected due to the complicated nature of the calibration system that

142 could not be described by available closed form solutions.

\subsection{Flexible tunnel loading regime}

145 Figures $4 \mathrm{a}$ and $4 \mathrm{~b}$ present the loading set ups used for the calibration of the bending moment 146 and axial force strain gauges of the flexible tunnel, respectively.

a.

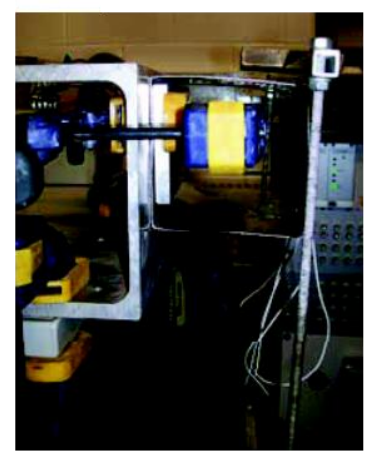

c. d.

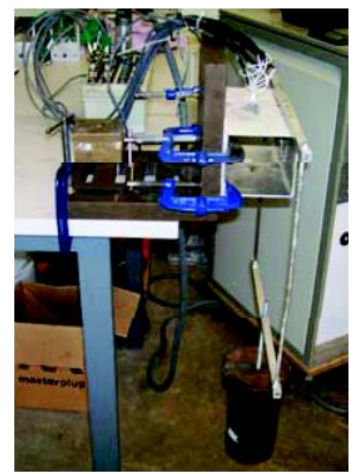

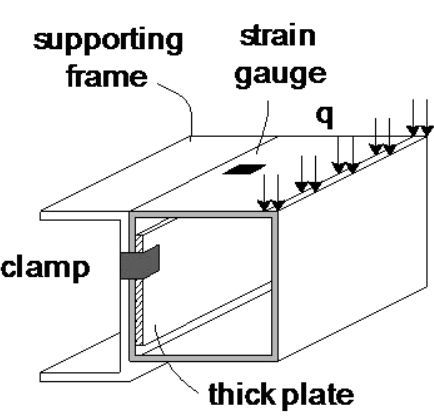

thick plate

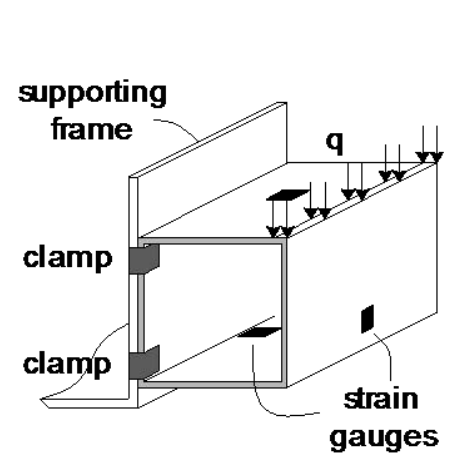

b.
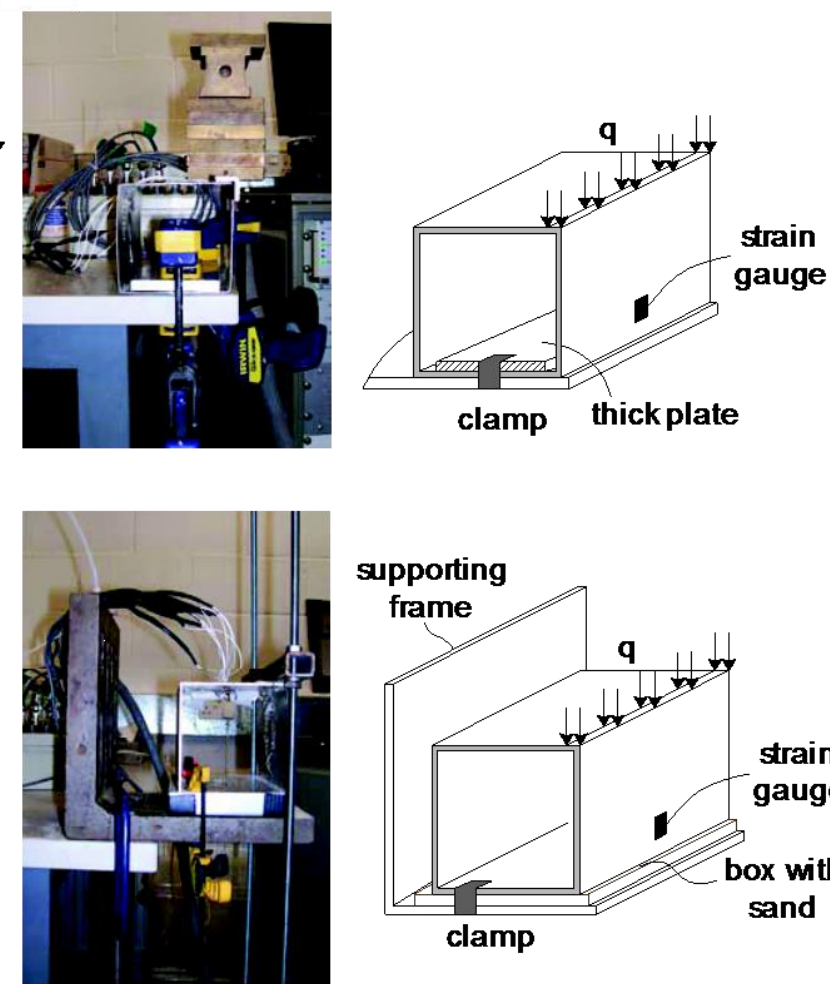

147

148

149

150

151

152

153

154

155

156

Fig. 4. Static configurations for the calibration of (a) the bending moment gauges of the flexible tunnel, (b) the axial force gauges of the flexible tunnel, (c) the bending moment gauges of the stiff tunnel, (d) the axial force gauges of the stiff tunnel

To calibrate the bending moment strain gauges, one tunnel wall was clamped to a rigid frame. The loading was introduced on the free side of the tunnel using a frame (to distribute the load along the length of the tunnel), consequently forming a 'cantilever static system' for the wall containing the strain gauge being calibrated (Fig. 4a). A thick aluminum plate was introduced between the clamps and the tunnel to avoid stress concentrations in the tunnel 
157 lining near the connections that could cause local yielding. This configuration resulted in a 158 fixed connection for almost the entirety of the tunnel wall.

A similar configuration was used for the calibration of the axial force strain gauges (Fig. 4b). The tunnel base slab was fixed using clamps, while a thick aluminum plate was introduced between the clamps and the tunnel to avoid stress concentrations near the fixities, similar to the bending moment case. The loading was introduced along the upper edge of the wall containing the strain gauge under calibration.

Each loading-unloading procedure was performed twice, so as to check the repeatability of the gauges response, while to calibrate all the strain gauges, the tunnel was appropriately rotated and clamped for each case. The calibration procedure was performed before the main centrifuge test, while no post test calibration was performed, as the tunnel collapsed during the actual test (Tsinidis et al., 2015b).

\subsection{Rigid tunnel loading regime}

Figures $4 \mathrm{c}$ and $4 \mathrm{~d}$ present the loading set ups used for the calibration of the bending moment and axial force strain gauges of the rigid tunnel. To calibrate the bending moment strain gauges, one tunnel wall was clamped using four points (upper and lower corner at each end) to a rigid frame (Fig. 4c). The loading was introduced on the free side of the tunnel using a frame. This configuration allowed the calibration of all the bending moment strain gauges simultaneously. The loading-unloading procedure was performed twice to check the repeatability of the gauges response, while the model was re-clamped and loaded several times, changing each time the "fixed side wall". This procedure allowed multiple records for different loading patterns for each strain gauge to be collated.

A set-up similar to the flexible tunnel configuration was used for the calibration of the axial force strain gauges (Fig. 4d). The tunnel was seated on a small box containing compacted sand, while the base slab was held down (in case of uplifting during loading) with clamps at both ends of the tunnel. The solution involving the sand box at the base of the tunnel was implemented due to the sand that had been stuck along the external face of the tunnel, which in addition to the relatively high rigidity of the tunnel lining would have resulted to stress concentrations (e.g. 'stress bridging') affecting the strain gauge recording response, if a rigid flat surface (as in the case of the flexible tunnel) had been used under the tunnel instead. Indeed, testing the gauges without the sand box at the base did result in a much more scattered response. The loading was introduced upon the wall containing the under calibration strain gauge. 
Similar to the other cases, each loading-unloading procedure was performed twice, so as to check the repeatability of the gauges response, while to calibrate all the strain gauges, the tunnel was properly rotated and clamped for each case. Both pre- and post-test calibration was performed to check the repeatability of the gauges response. Care was taken during the calibration procedure to ensure the loading magnitude was sufficient to obtain clear measurements of the strains without causing any yielding of the model-tunnel.

\subsection{Numerical analysis}

The internal forces at each gauge position were computed through numerical static analyses of the structural models. The results were plotted against the measured voltage change in order to evaluate each gauge calibration factor. The structural models were simulated in ABAQUS (ABAQUS, 2012) with elastic shell elements, taking into account the exact supports and loading positions of each test case (Fig. 5). The static load caused by the weight was introduced on the loaded area of the tunnel lining as an equivalent pressure, $q$, thus resembling the actual loading configuration imposed during the calibration procedure.
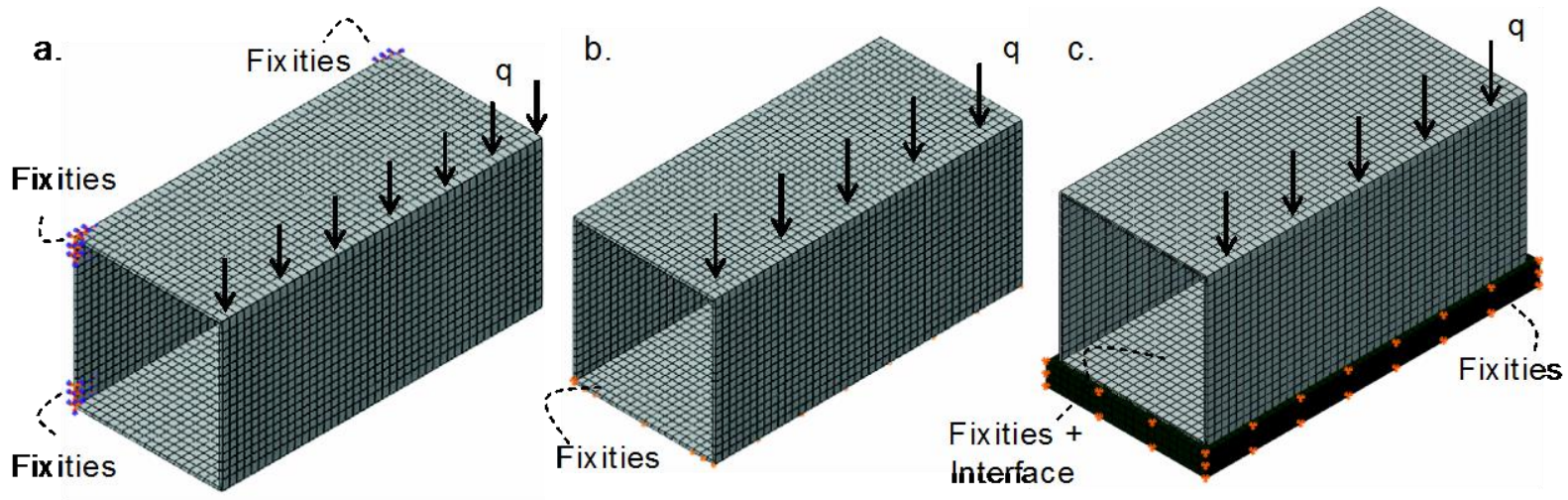

Fig. 5. (a) Numerical model of the rigid tunnel bending moment strain gauges calibration configuration, (b) simplified numerical model of the rigid tunnel axial strain gauges calibration configuration, (c) rigorous numerical model of the rigid tunnel axial strain gauges calibration configuration

The precise simulation of the actual support system by the numerical analyses is the key in order to determine the most accurate value for the internal force at the strain gauge locations. To replicate the static system used during the calibration procedure of the flexible tunnel bending moment strain gauges, the transnational and rotational degrees of freedom of the tunnel along the clamped area (restrained with the thick aluminum plate as discussed) were fixed, while a similar procedure was also used for the axial force strain gauges. 
For the simulation of the bending moment strain gauges calibration procedure of the stiff tunnel, both the transnational and rotational degrees of freedom of the clamped areas were fixed (Fig 5a). To examine the effect of the sand box at the base of the tunnel (used during the calibration of the axial force strain gauges) two cases were investigated; during the first case, the base slab of the tunnel was simply fixed in terms of vertical displacement (Fig. 5b), while in the second case the sand layer under the tunnel was also simulated with solid elements (Fig. 5c). The sand-tunnel interface was adequately modelled using a finite-sliding hard conduct formulation embedded in ABAQUS (ABAQUS, 2012). The model precludes penetration between the interacting surfaces, while it allows for separation. The tangential behaviour was simulated implementing the classical isotropic Coulomb friction model. The friction coefficient $\mu$ was set equal to 0.62 , based on the friction angle of the specific sand fraction. The restraints that were induced by the clamps (e.g. end sides) were simulated with proper kinematic constrains between the model tunnel nodes and the base of the sand layer model. The sand elastic properties were parametetrically checked, ranging between values corresponding to either loose or dense sand.

Fig. 6 portrays typical deformed shapes of the stiff model tunnel, along with the distributions of the internal forces for pressure loadings corresponding to a 1 kilogram of weight. The effect of the static model configuration on the axial force of the stiff tunnel is highlighted by comparing the numerical predictions between the simplified model and the detailed model (Figs. $6 \mathrm{~b}$ and c). The presented results refer to a relatively loose sand bed. Generally, the difference on the computed axial force between the more accurate and the simple model was less than $5 \%$, indicating that the presence of the sand bed did not had a

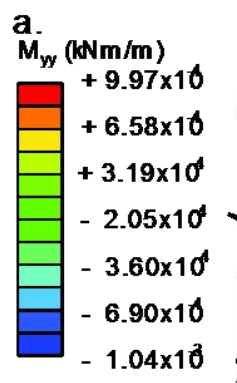

Fixities significant impact on the simulation.

Fig. 6. Representative deformed shapes of the stiff tunnel for different loading configurations, (a) contour diagram tunnel bending moment $M_{y y}$, (b) contour diagram of the axial force computed by the simplified model, (c) contour diagram of the axial force computed by the detailed model 


\subsection{Calibration factors}

248 Fig. 7 presents representative examples of Voltage-internal force calibration curves, for axial

249 force and bending moment strain gauges attached to both the flexible and the rigid tunnel.
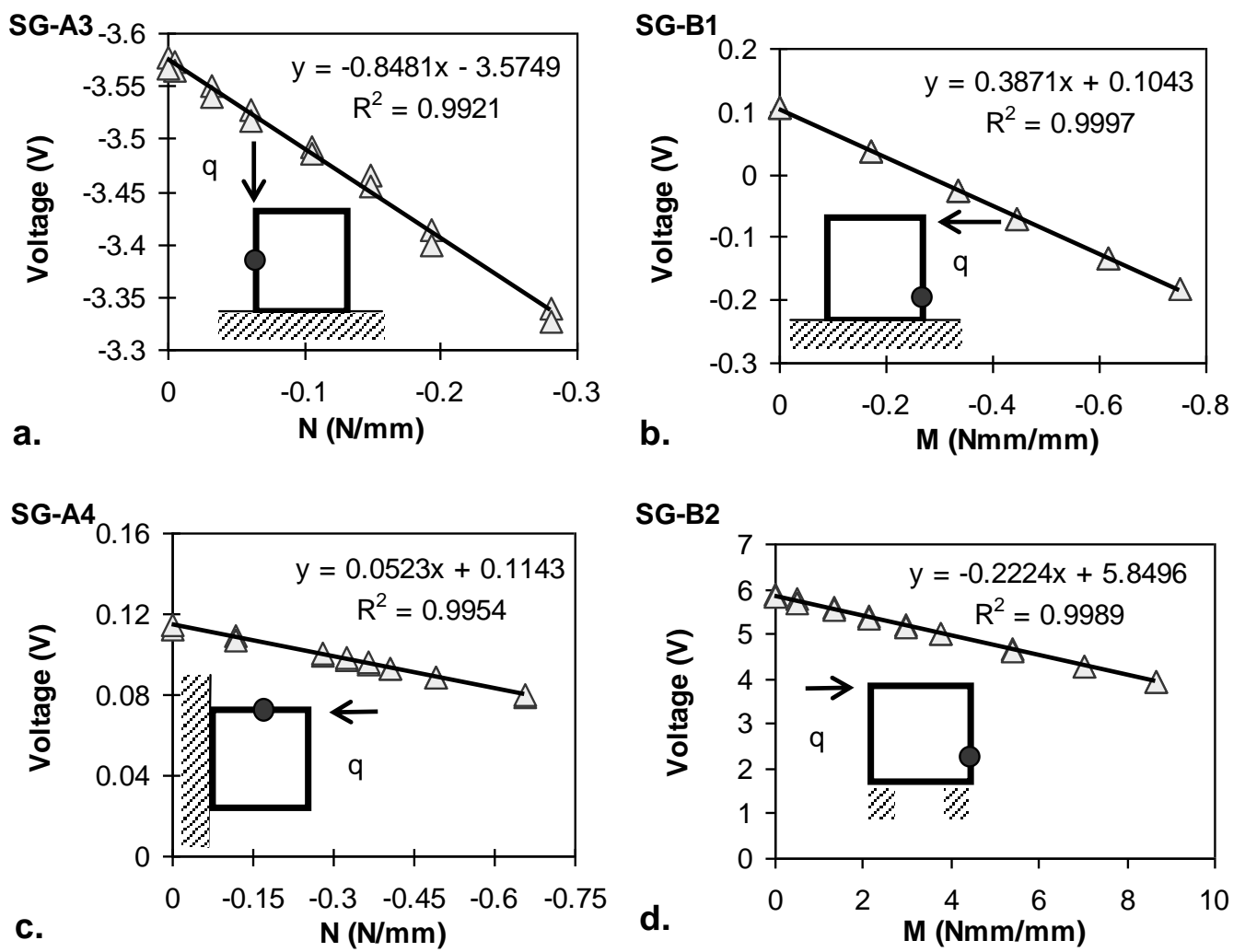

Fig. 7. Voltage-internal force calibration curves for the flexible tunnel strain gauges $(a, b)$ and the rigid tunnel strain gauges $(\mathrm{c}, \mathrm{d})$

Tables 1 and 2 summarize the calibration factors estimated for the flexible tunnel, while in Tables 3 and 4 the calibration factors of the rigid tunnel strain gauges are presented. With regard to the flexible tunnel, the comparisons between the different loading repeatations reveal differences up to $4-5 \%$ for the bending moment strain gauges and up to $30 \%$ for the axial force strain gauges. Similar observations are made regarding the differences between the recorded responses of the rigid tunnel strain gauges.

Generally, the calibration factors of the axial strain gauges were found to be more scattered compared to the bending moment strain gauges. This is attributed to difficulties regarding the axial loading of the tunnel-models. As already stated, the loading should be 'strong' enough to obtain clear measurements of the axial strains, without however, jeopardizing the elastic response of the model (e.g. yielding). In addition, problems related to the support systems used during the calibration procedure or stress concentrations caused by the sand stuck around the tunnel could affect the estimated factors. 
Table 1. Axial force strain gauge calibration factors for the flexible tunnel

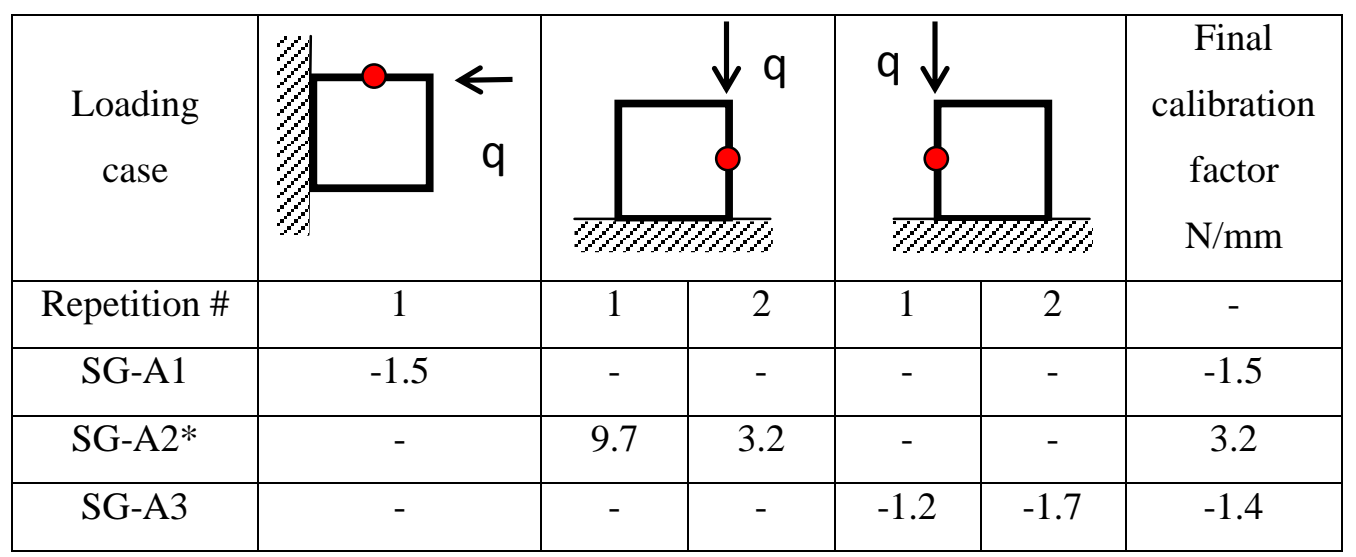

* probably malfunctioned

269 Table 2. Bending moment strain gauge calibration factors for the flexible tunnel

\begin{tabular}{|c|c|c|c|c|c|}
\hline $\begin{array}{l}\text { Loading } \\
\text { case }\end{array}$ & & $q$ & $\downarrow$ & $\frac{1}{1 /}$ & $\begin{array}{c}\text { Final } \\
\text { calibration } \\
\text { factor } \\
\mathrm{Nmm} / \mathrm{mm}\end{array}$ \\
\hline Repetition \# & 1 & 2 & 1 & 2 & - \\
\hline SG-B1 & 2.50 & 2.58 & - & - & 2.54 \\
\hline SG-B2 & - & - & 2.69 & 2.70 & 2.70 \\
\hline
\end{tabular}

271 Table 3. Axial force strain gauge calibration factors estimated before and after test for the rigid tunnel

272 (factor for pre test calibration procedure / factor for post test calibration procedure)

\begin{tabular}{|c|c|c|c|c|c|c|c|c|c|c|c|}
\hline $\begin{array}{l}\text { Loading } \\
\text { case }\end{array}$ & $\mathrm{q} \downarrow$ & & 交 & $\stackrel{q}{\leftarrow}$ & & $\downarrow q$ & 多 & & $\leftarrow$ & \multicolumn{2}{|c|}{$\begin{array}{c}\text { Final calibration } \\
\text { Factors } \\
(\mathrm{N} / \mathrm{mm})\end{array}$} \\
\hline Repetition & 1 & 2 & 1 & 2 & 1 & 2 & 1 & 2 & 3 & $\begin{array}{l}\text { Pre } \\
\text { test }\end{array}$ & $\begin{array}{l}\text { Post } \\
\text { test }\end{array}$ \\
\hline SG-A1 & $\begin{array}{l}24.8 / \\
19.6\end{array}$ & $\begin{array}{l}24.0 / \\
22.0\end{array}$ & - & - & - & - & - & - & - & 24.4 & 20.8 \\
\hline SG-A2 & - & - & $\begin{array}{l}15.8 / \\
17.1\end{array}$ & $\begin{array}{l}18.6 / \\
26.0\end{array}$ & - & - & - & - & - & 17.2 & 21.6 \\
\hline SG-A3 & - & - & - & - & $\begin{array}{l}14.6 / \\
18.5\end{array}$ & $\begin{array}{l}16.1 / \\
14.3\end{array}$ & - & - & - & 15.3 & 16.4 \\
\hline SG-A4 & - & - & - & - & - & - & $\begin{array}{c}17.0 / \\
24\end{array}$ & $\begin{array}{c}19.1 / \\
25\end{array}$ & $\begin{array}{c}15.9 / \\
-\end{array}$ & 17.3 & 25 \\
\hline
\end{tabular}


Table 4 Bending moment gauges calibration factors estimated before and after test for the rigid tunnel

275 (factor for pre test calibration procedure / factor for post test calibration procedure)

\begin{tabular}{|c|c|c|c|c|c|c|c|c|}
\hline $\begin{array}{c}\text { Calibration } \\
\text { factors }\end{array}$ & $\uparrow$ & $\mathbb{Z}$ & $q$ & & & $\downarrow$ & \multicolumn{2}{|c|}{$\begin{array}{c}\text { Final calibration } \\
\text { factors } \\
(\mathrm{Nmm} / \mathrm{mm})\end{array}$} \\
\hline Repetition & 1 & 2 & 1 & 2 & 1 & 2 & $\begin{array}{l}\text { Pre } \\
\text { test }\end{array}$ & $\begin{array}{l}\text { Post } \\
\text { test }\end{array}$ \\
\hline SG-B1 & $\begin{array}{l}4.50 / \\
4.50\end{array}$ & $\begin{array}{l}4.60 / \\
4.00\end{array}$ & $\begin{array}{l}4.90 / \\
4.90\end{array}$ & $\begin{array}{l}5.10 / \\
5.20\end{array}$ & $\begin{array}{l}4.70 / \\
5.40\end{array}$ & $\begin{array}{l}4.70 / \\
5.40\end{array}$ & 4.74 & 4.90 \\
\hline SG-B2 & $\begin{array}{l}-4.90 / \\
-5.20\end{array}$ & $\begin{array}{l}-5.00 / \\
-5.00\end{array}$ & $\begin{array}{l}-4.50 / \\
-4.80\end{array}$ & $\begin{array}{l}-4.60 / \\
-4.90\end{array}$ & $\begin{array}{l}-4.50 / \\
-4.90\end{array}$ & $\begin{array}{l}-4.50 / \\
-4.90\end{array}$ & -4.66 & -4.94 \\
\hline SG-B3* & $\begin{array}{l}0.10 / \\
3.20\end{array}$ & $\begin{array}{l}0.10 / \\
3.20\end{array}$ & $\begin{array}{l}0.10 / \\
9.00\end{array}$ & $\begin{array}{l}0.10 / \\
10.30\end{array}$ & $\begin{array}{l}-1.40 / \\
-26.00\end{array}$ & $\begin{array}{l}-1.10 / \\
-23.00\end{array}$ & - & - \\
\hline SG-B4 & $\begin{array}{l}4.30 / \\
4.60\end{array}$ & $\begin{array}{l}4.30 / \\
4.60\end{array}$ & $\begin{array}{l}4.70 / \\
4.50\end{array}$ & $\begin{array}{l}4.70 / \\
4.90\end{array}$ & $\begin{array}{l}5.00 / \\
5.40\end{array}$ & $\begin{array}{l}5.20 / \\
5.40\end{array}$ & 4.71 & 4.92 \\
\hline
\end{tabular}

*broken

The calibration factors derived after the main centrifuge tests (for the rigid tunnel) were slightly higher compared to the pre-test values, with the deviations being larger for the axial force gauges. This could be attributed to a permanent lining response as a consequence of severe loading during the earthquake loading. Therefore, the pre-test calibration factors were adopted for the final interpretation of the lining recorded response data. In particular, a mean value was adopted for each gauge factor, accounting for all the estimated factors of each

\section{Representative records}

Figures $7 \mathrm{a}$ and $7 \mathrm{~b}$ illustrate representative time histories of the dynamic bending moments, recorded near the right side-wall bottom corner of both the flexible and the rigid tunnels. Positive values represent bending moment with tensile stress increments for the internal lining face. Records indicate significant locked-in bending induced strain after shaking finished, due to the soil densification and yielding around the tunnel. Representative dynamic axial force time histories recorded at the side-walls of the rigid tunnel are presented in Fig. 7c. In this case, positive values represent tensile axial force. The records are out of phase, indicating a rocking mode of vibration for the tunnel in addition to the pure racking distortion. A thorough 
discussion of the recorded response may be found in relevant publications (e.g. Tsinidis et al., $2962014,2015 b ; 2015 c)$.
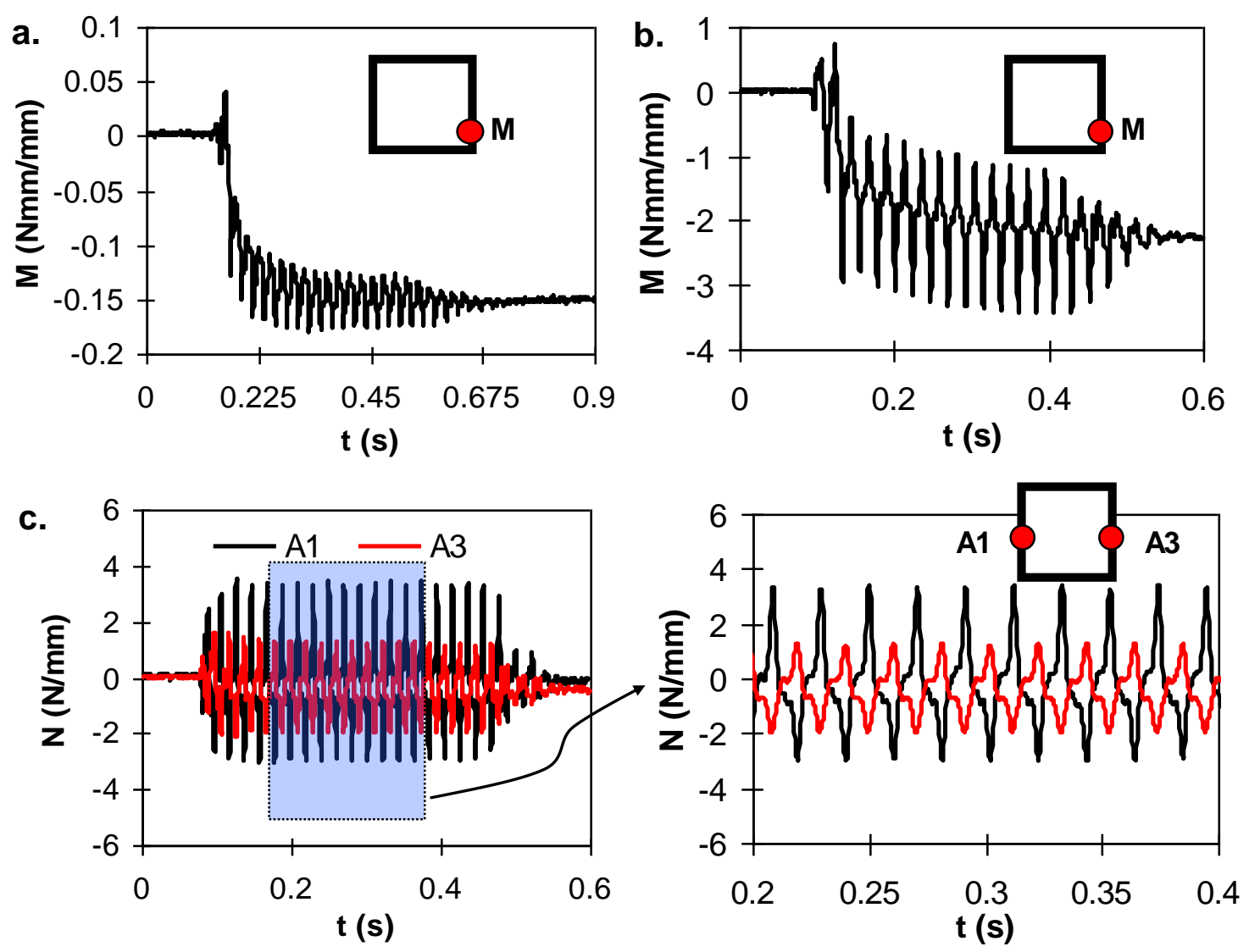

Fig. 8. Dynamic bending moment time histories recorded near the right side-wall bottom corner of the (a) flexible and the (b) rigid tunnel, (c) dynamic axial force time histories recorded on the side-walls of the rigid tunnel

\section{Conclusions}

303 A series of dynamic centrifuge tests were performed on square model tunnels embedded in 304 dry sand. This technical note presented the calibration procedure followed for the resistance strain gauges, which were attached to the model tunnels to record the lining internal forces at several crucial locations during the tests. Strain gauge calibration factors were derived for simple static loading patterns. A crucial step within this calibration procedure was the rational evaluation of the model response due to these simplified loading patterns (e.g. computation of internal forces at strain gauges locations). This evaluation was performed by means of 3D numerical analysis of the static configurations, simulating as accurately as possible the supports and loading regimes. Accounting for the complicated nature of the calibration system and the inexistence of plausible analytical closed form solutions, numerical analysis 
was mandatory. The combination of experimental testing and numerical analysis was found to

314 be quite satisfactorily in calibration of this model, as the recorded lining forces were found to be in good agreement with the theoretically expected behaviour. The main conclusion of this work is that combined experimental testing and numerical analysis can be used quite efficiently for the calibration of complex structural models, as well as for cases where no analytical closed form solutions are available. A crucial point for the efficiency of this approach is the proper simulation of the static configurations (e.g. supports, loading regimes etc).

\section{Acknowledgements}

The research leading to these results has received funding from the European Community's Seventh Framework Programme [FP7/2007-2013] for access to the Turner Beam Centrifuge, Cambridge, UK under grant agreement $n^{\circ} 227887$ [SERIES: Seismic Engineering Research Infrastructures for European Synergies; www.series.upatras.gr/TUNNELSEIS]. The technical support received by the Technicians of the Schofield Centre is gratefully acknowledged.

\section{References}

ABAQUS (2010) ABAQUS: theory and analysis user's manual version 6.10. Dassault Systèmes SIMULIA Corp, Providence

Abuhajar O, El Naggar H, Newson T (2015) Seismic soil-culvert interaction. Canadian Geotechnical Journal 52:1-19

Adalier K, Abdoun T, Dobry R, Phillips R, Yang D, Naesgaard E (2003) Centrifuge modeling for seismic retrofit design of an immersed tube tunnel. International Journal of Physical Modelling on Geotechnics 3(2):23-35

Chen G, Wang Z, Zuo X, Du X, Gao H (2013) Shaking table test on seismic failure characteristics of a subway station structure in liquefiable ground. Earthquake Engineering and Structural Dynamics 42:1489-1507

Chen ZY, Shen H (2014) Dynamic centrifuge tests on isolation mechanism of tunnels subjected to seismic shaking. Tunnelling and Underground Space Technology 42:67-77

Chian SC, Madabhushi SPG (2012) Effect of buried depth and diameter on uplift of underground structures in liquefied soils. Journal of Soil Dynamics and Earthquake Engineering 41:181-190

Chou JC, Kutter BL, Travasarou T, Chacko JM (2010) Centrifuge modeling of seismically induced uplift for the BART transbay tube. Journal of Geotechnical and Geoenvironmental Engineering 137(8):754-765 
Cilingir U, Madabhushi SPG (2011a) A model study on the effects of input motion on the seismic behaviour of tunnels. Journal of Soil Dynamics and Earthquake Engineering 31:452-462

Cilingir U, Madabhushi SPG (2011b) Effect of depth on the seismic response of square tunnels. Soils and Foundations 51(3):449-457

Cilingir U, Madabhushi SPG (2011c) Effect of depth on the seismic response of circular tunnels. Canadian Geotechnical Journal 48(1):117-127

Lanzano G, Bilotta E, Russo G, Silvestri F, Madabhushi SPG (2012) Centrifuge modeling of seismic loading on tunnels in sand. Geotechnical Testing Journal 35(6):10-26

Shibayama S, Izawa J, Takahashi A, Takemura J and Kusakabe O (2010) Observed behavior of a tunnel in sand subjected to shear deformation in a centrifuge. Soils and foundations 50(2):281-294

Tsinidis G, Heron C, Pitilakis K, Madabhushi SPG (2014) Physical modeling for the evaluation of the seismic behavior of square tunnels. In: Ilki A and Fardis M (eds) Seismic evaluation and rehabilitation of structures, Geotechnical Geological and Earthquake Engineering, 26, Springer International Publishing, Switzerland, pp 389-406

Tsinidis G, Rovithis E, Pitilakis K, Chazelas JL (2015a) Dynamic response of shallow rectangular tunnels in sand by centrifuge testing, in: Taucer F, Apostolska R (eds) Experimental research in earthquake engineering - EU-SERIES concluding workshop, Geotechnical Geological and Earthquake Engineering, 35, Springer International Publishing, Switzerland, pp 493-507

Tsinidis G, Heron C, Pitilakis K, Madabhushi SPG (2015b) Centrifuge modelling of the dynamic behavior of square tunnels in sand. In: Taucer F and Apostolska R (eds) Experimental research in earthquake engineering - EU-SERIES concluding workshop, Geotechnical Geological and Earthquake Engineering, 35, Springer International Publishing, Switzerland, pp 509-523

Tsinidis G, Pitilakis K, Madabhushi G, Heron C (2015c) Dynamic response of flexible square tunnels: centrifuge testing and validation of existing design methodologies. Geotechnique 65(5):401-417

Ulgen D, Saglam S and Ozkan MY (2015) Dynamic response of a flexible rectangular underground structure in sand: centrifuge modeling. Bulletin of Earthquake Engineering 13:2547-2566 